\title{
Using transfer entropy to measure information flows between financial markets
}

\author{
Thomas Dimpfl * \\ Franziska J. Peter *
}

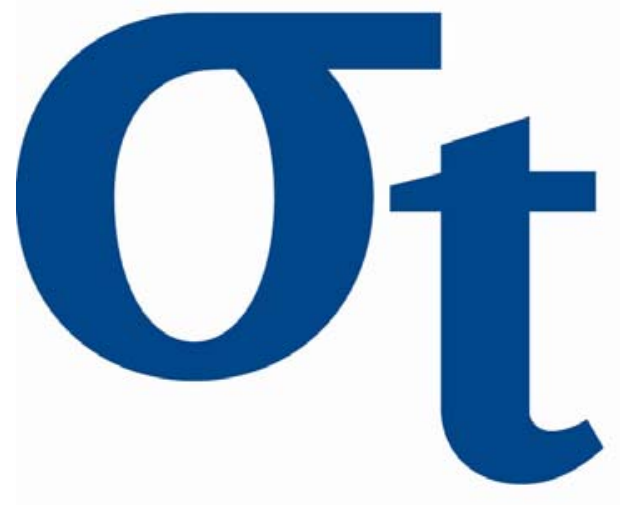

* Universität Tübingen, Germany
9)

寸

6

m

ㄴ

0

This research was supported by the Deutsche Forschungsgemeinschaft through the SFB 649 "Economic Risk".

http://sfb649. wiwi.hu-berlin. de ISSN 1860-5664 


\title{
Using transfer entropy to measure information flows between financial markets
}

\author{
Thomas Dimpfl* Franziska J. Peter*
}

August 23, 2012

\begin{abstract}
We use transfer entropy to quantify information flows between financial markets and propose a suitable bootstrap procedure for statistical inference. Transfer entropy is a model-free measure designed as the Kullback-Leibler distance of transition probabilities. Our approach allows to determine, measure and test for information transfer without being restricted to linear dynamics. In our empirical application, we examine the importance of the credit default swap market relative to the corporate bond market for the pricing of credit risk. We also analyze the dynamic relation between market risk and credit risk proxied by the VIX and the iTraxx Europe, respectively. We conduct the analyses for pre-crisis, crisis and post-crisis periods.
\end{abstract}

Keywords: entropy; information flow; non-linear dynamics; price discovery; credit risk; CDS.

JEL classifications: C14, G15

\footnotetext{
${ }^{*}$ University of Tübingen

Corresponding author: Franziska Julia Peter, University of Tübingen, Department of Statistics, Econometrics and Empirical Economics, Mohlstraße 36, 72074 Tübingen, Germany, Phone: +49 707129 78165. Fax: +49 707129 5546. Email: franziska-julia.peter@uni-tuebingen.de.

We thank participants of the annual meeting of the Society of Nonlinear Dynamics and Econometrics, Washington 2011, of the interdisciplinary workshop on Econometric and Statistical Modelling of Multivariate Time Series, UCL Louvain-la-Neuve, 2011, and of the 2012 Midwest Financial Association meeting, New Orleans, and two anonymous referees for helpful comments. This research project is funded by the German Research Foundation (DFG) through grant GR 2288, data are provided through the DFG SFB 649 "Economic Risk".
} 


\section{Introduction}

Detecting and measuring interactions between different time series is the subject of research in various areas. In finance the informational link between different markets is of particular interest. Yet, there is only a small range of methods to empirically examine these linkages. The predominant concept is that of Granger causality (see Granger, 1969) which is widely applied to detect lead-lag relationships between time series. However, the insights that can be gained from this method are limited to the mere existence of information flows rather than their quantification. An actual measure for information transfer between financial markets exists only for a particular setting of empirical applications: if prices in different markets refer to the same underlying asset, price discovery measures such as the Hasbrouck (1995) information shares can be used to determine the informational dominant market. This approach requires a cointegration relationship between the different time series and only provides a sensible interpretation of the results if cointegration is implied by theory and supported by the data. Furthermore, Granger causality and price discovery measures are based on a Vector Autoregressive (VAR) or Vector Error Correction Model (VECM) framework which imposes rather restrictive assumptions concerning the underlying (linear) dynamics.

As an alternative we propose to apply the concept of transfer entropy to measure information flows between different financial time series. Transfer entropy is a model-free measure which is designed as the Kullback-Leibler distance of transition probabilities. Under weak assumptions this approach allows to quantify information transfer without being restricted to linear dynamics. It is therefore an appealing tool if the assumptions required by the standard models are not supported by the data. There exist only few studies that apply transfer entropy within the context of financial markets. Kwon and Yang (2008a), for example, analyze the information flow between the S\&P 500, the Dow Jones index and selected individual companies on a daily basis. Baek, Jung, Kwon, and Moon (2005) examine

the information transfer between groups of NYSE listed stocks to determine market sensitive and market leading companies, and Kwon and Yang (2008b) investigate 
the strength and direction of information transfer between various stock indices using transfer entropy. The measurement of interactions between the Indian stock and commodity market is the subject of a study by Reddy and Sebastin (2009).

In all these finance studies, statistical inference has not been accounted for. We address this issue and propose to bootstrap the underlying Markov process (see Horowitz, 2003) in order to derive the distribution of the estimates and assess the statistical significance of the estimated information flows. Furthermore, we address the issue of correcting for small sample bias of the transfer entropy estimator in a novel way: we suggest to use the bootstrapped distribution under the null hypothesis of no information flow to correct for finite sample bias rather than using shuffled data which has been the standard procedure in the literature on information theory so far (see, inter alia, Papana, Kugiumtzis, and Larsson, 2001).

This paper includes two empirical applications of the transfer entropy methodology to measure information flows between financial markets. First, we examine the information flows between the credit default swap (CDS) and the bond market, analyzing data on 27 iTraxx Europe companies. Both markets reflect the price of credit risk for the same reference entity. Therefore, as outlined in Blanco, Brennan, and Marsh (2005), assuming a cointegration relationship between the time series is plausible. Our dataset consists of a sample of CDS and bond market data of 27 European companies from January 2004 to December 2011. Due to market imperfections cointegration is not always supported for each and every company (as is also the case in the study of Blanco et al., 2005) so that a VECM cannot be reasonably applied. Using transfer entropy, we find in general significant bi-directional information flow between the CDS and the bond market. Our results point towards a slight dominance of the CDS market, in particular during the financial crisis, and thus are in line with previous findings in the literature like Blanco et al. (2005) and Coudert and Gex (2010).

In our second application we analyze factors that might influence the CDS market by examining the link between market risk and credit risk. Thereby, we follow Figuerola-Ferrett and Paraskevopoulos (2009) and consider the dynamic relation between iTraxx and VIX. Again, we draw on a long sample of iTraxx and 
VIX data ranging from March 2005 to November 2011. We find that in general the transfer entropy estimates for the flow of information from the VIX to the iTraxx are statistically significant and exceed the information flow from the iTraxx to the VIX.

The remainder of the paper is organized as follows. Section 2 introduces the concept of transfer entropy. Diagnostics and inference are discussed in Section 3. Section 4 contains the empirical applications and Section 5 concludes.

\section{Measuring information flows by transfer entropy}

The concept of transfer entropy is best understood within the context of information theory. In the era of early telecommunications, when communication was based on Morse code, Hartley (1928) introduced a measure for information relying on the logarithm of the number of all possible symbol sequences that can occur. The general aim was to optimally encode messages such that they can be transmitted more quickly. For that purpose it was necessary to quantify the information that can be derived from a specific sequence of transmitted symbols.

Consider the following example: when flipping a fair coin, there are two equally likely outcomes, head or tail. According to Hartley (1928) the information (denoted by $\mathrm{H}$ ) that can be gained from flipping a coin once is given by $\mathrm{H}=\log (2)$. If the base of the $\operatorname{logarithm}$ is $2, \mathrm{H}=\log _{2}(2)=1$ and the measurement unit will be bits. Consequently, $n$ flips of the coin yield $n$ bits of information $\left(\mathrm{H}=\log \left(2^{n}\right)=\right.$ $n \times \log _{2}(2)=n$ ) and we would need $n$ binary digits to specify the resulting sequence (such as 1 for heads and 0 for tails).

In the case of symbols that are not equally likely, but occur with different probabilities $p_{j}$, the amount of information gained from a specific symbol $j$ is given by $\log \left(1 / p_{j}\right)$. The average amount (per symbol) of information one can get from

such a sequence is defined as $\mathrm{H}=\sum_{j=1}^{n} p_{j} \log \left(\frac{1}{p_{j}}\right)$, where $n$ is the number of distinct symbols. This leads to the general formula of Shannon (1948): assume that $J$ is a discrete variable with probability distribution $p(j)$, where $j$ labels the different 
values (or states) that $J$ can take. Then the Shannon entropy

$$
\mathrm{H}_{\mathrm{J}}=-\sum_{j} \mathrm{p}(j) \times \log _{2} \mathrm{p}(j)
$$

gives the average number of bits needed to optimally encode independent draws from the distribution of $J$. In the following "log" denotes the base 2 logarithm and the summation runs over the distinct values of $J .{ }^{1}$ Shannon's formula in Equation (1) is a measure for uncertainty. The more bits are needed to optimally encode realizations of the process, the higher is the uncertainty about possible realizations of $J$. The largest amount of uncertainty will be given if all values of $J$ are equally likely, i.e., if $J$ is uniformly distributed and a random draw produces any realization of $J$ with the same probability.

The link between uncertainty and information is established drawing on the Kullback-Leibler distance (see Kullback and Leibler, 1951). It defines the excess amount of bits needed in the encoding when erroneously assuming a probability distribution $q(j)$ of $J$ different from $p(j)$ :

$$
\mathrm{K}_{\mathrm{J}}=\sum_{j} \mathrm{p}(j) \times \log \frac{\mathrm{p}(j)}{\mathrm{q}(j)}
$$

In the bivariate case, let $I$ and $J$ be two discrete random variables with marginal probability distributions $p(i)$ and $p(j)$ and joint probability $p_{I J}(i, j)$. The mutual information of the two processes is defined as the reduction in uncertainty compared to the case where both processes are independent, i.e. where the joint distribution is given by the product of the two marginal distributions, $p_{I J}=p(i) p(j)$. The corresponding Kullback entropy which is known as the formula for mutual information is given by

$$
\mathrm{M}_{\mathrm{IJ}}=\sum_{i, j} \mathrm{p}(i, j) \times \log \frac{\mathrm{p}(i, j)}{\mathrm{p}(i) \mathrm{p}(j)}
$$

\footnotetext{
${ }^{1}$ The choice of the basis does not change the information contained in the measure, but only alters the unit of measurement: base 2 logarithm indicates bits, base 10 gives digits and the base of the natural logarithm yields nats.
} 
where the summation runs over all possible values $i$ and $j$. Mutual information can detect any form of statistical dependency between different variables. However, it is a symmetric measure and therefore does not deliver any evidence concerning the dynamics of information exchange.

In the context of time series, dynamical structure can be introduced by considering transition probabilities (see Schreiber, 2000). Let $I$ be a stationary Markov process of order $k$, then it holds for the probability to observe $I$ at time $t+1$ in state $i$ conditional on the $k$ previous observations that $p\left(i_{t+1} \mid i_{t}, \ldots, i_{t-k+1}\right)=$ $p\left(i_{t+1} \mid i_{t}, \ldots, i_{t-k}\right)$. The average number of bits needed to encode one more time series observation if the previous values are known is given by

$$
\mathrm{h}_{\mathrm{I}}(k)=-\sum_{i} \mathrm{p}\left(i_{t+1}, i_{t}^{(k)}\right) \times \log \mathrm{p}\left(i_{t+1} \mid i_{t}^{(k)}\right)
$$

where $i_{t}^{(k)}=\left(i_{t}, \ldots, i_{t-k+1}\right)$. In the bivariate case Schreiber (2000) proposes to measure information flow from process $J$ to process $I$ by quantifying the deviation from the generalized Markov property $p\left(i_{t+1} \mid i_{t}^{(k)}\right)=p\left(i_{t+1} \mid i_{t}^{(k)}, j_{t}^{(l)}\right)$, where $l$ gives the order of the assumed Markov process for $J$. In the case of no information flow from $J$ to $I$ the transition probabilities of $I$ are not affected by previous observations of $J$. Schreiber (2000) then draws on the Kullback-Leibler distance to measure the deviation of the bivariate system from this assumption and derives the formula for transfer entropy as

$$
\mathrm{T}_{\mathrm{J} \rightarrow \mathrm{I}}(k, l)=\sum \mathrm{p}\left(i_{t+1}, i_{t}^{(k)}, j_{t}^{(l)}\right) \times \log \frac{\mathrm{p}\left(i_{t+1} \mid i_{t}^{(k)}, j_{t}^{(l)}\right)}{\mathrm{p}\left(i_{t+1} \mid i_{t}^{(k)}\right)} .
$$

$\mathrm{T}_{\mathrm{J} \rightarrow \mathrm{I}}$ consequently measures the information flow from process $\mathrm{J}$ to process I. Note that transfer entropy is an asymmetric measure. This means that by exchanging $J$ and $I$ and calculating $\mathrm{T}_{\mathrm{I} \rightarrow \mathrm{J}}(l, k)$ along with $\mathrm{T}_{\mathrm{J} \rightarrow \mathrm{I}}(k, l)$ we can infer the dominant direction of the information flow.

The transfer entropy measure in Equation (5) is derived for discrete data. In any economic application, the observed time series are, however, continuous. In order to apply transfer entropy, it is necessary to partition the data into discretized 
values. Motivated by the subsequent applications we present the partitioning into three bins. A higher number of bins is possible, but requires a considerably greater amount of data. To obtain the symbolically encoded series $S(t)$ a time series $x(t)$ is partitioned as follows:

$$
S(t)=\left\{\begin{array}{l}
1 \text { for } x(t) \leq q_{1} \\
2 \text { for } q_{1}<x(t)<q_{2} \\
3 \text { for } x(t) \geq q_{2}
\end{array} .\right.
$$

The symbolic encoding above replaces each value in the observed time series by a corresponding symbol $(A, B, C)$. The choice of the quantile should be motivated by the distribution of the data (see also Section 4). In order to check for robustness of the transfer entropy measure, the quantile can be varied.

\section{Diagnostics and Inference}

The choice of the block lengths (i.e. the order of the Markov process) $k$ and $l$ in Equation (5) is a crucial point when calculating transfer entropy measures. $k$ and $l$ will have to be large enough to capture the information flow between two time series. However, finite sample effects will become more severe when increasing the block length. Then again, if $k$ in $\mathrm{T}_{\mathrm{J} \rightarrow \mathrm{I}}(k, l)$ is too low, information contained in the past values of $I$ might erroneously be assigned to come from $J$. This will not happen if $I$ is independent from itself with a delay of $k$. We therefore base the selection of the appropriate block length on the calculation of mutual information between the time series and its own series with delay $k$ :

$$
\mathrm{M}_{\mathrm{II}_{k}}(k)=\sum_{i, i_{k}} \mathrm{p}\left(i, i_{k}\right) \times \log \frac{\mathrm{p}\left(i, i_{k}\right)}{\mathrm{p}(i) \mathrm{p}\left(i_{k}\right)},
$$

where $I_{k}$ denotes the series $I$ with delay $k$. The value of $k$ associated with the first local minimum of this function is used as the optimal block length (see Fraser and Swinney, 1986, Reddy and Sebastin, 2009). 
The transition probabilities needed to calculate transfer entropy measures have to be estimated from a specific sample. Marschinski and Kantz (2002) show that the transfer entropy estimates derived in Equation (5) are likely to be biased due to small sample effects. They propose a modification, the effective transfer entropy

$$
\mathrm{ET}_{\mathrm{J} \rightarrow \mathrm{I}}^{\text {shuffed }}(k, l):=\mathrm{T}_{\mathrm{J} \rightarrow \mathrm{I}}(k, l)-\mathrm{T}_{\mathrm{J}_{\text {shuffled }} \rightarrow \mathrm{I}}(k, l)
$$

where $T_{J_{\text {shuffed }} \rightarrow I}$ indicates the transfer entropy with shuffled series $J$. Shuffling is implemented by randomly drawing realizations from the distribution of $J$ and realigning them to generate a new time series. Thus, all statistical dependencies between the two (time) series are destroyed. $\mathrm{T}_{\mathrm{J}_{\text {shuffed }} \rightarrow \mathrm{I}}(k, l)$ consequently converges to zero with increasing sample size and any non-zero value of $\mathrm{T}_{\mathrm{J}_{\text {shuffled }} \rightarrow \mathrm{I}}(k, l)$ is due to small sample effects. It is common practice to shuffle the data several times and use the transfer entropy estimate averaged over the simulations to estimate the bias and calculate effective transfer entropy. However, shuffling the data destroys the dependencies within the univariate time series as well. A more accurate detection of the finite sample bias is provided by a setting that provides the distribution of the transfer entropy estimates under the assumption of no information flow while retaining the dynamics of the univariate time series. This issue is directly related to the question of how to conduct inference concerning the estimated information flows.

The straightforward approach is a standard block bootstrap along the lines of Carlstein (1986). However, as outlined by Lahiri (1999), standard methods such as non-overlapping-block bootstraps, moving-block bootstraps or bootstraps with random block length produce biased estimates. We therefore draw on Horowitz (2003) and bootstrap the underlying Markov process. This means that we simulate process $J$ based on the calculated transition probabilities, whereby the dependencies between $J$ and $I$ are destroyed, but the dynamics of the series $J$ is retained. Transfer entropy is then estimated again using the simulated time series. Repeating this procedure yields the distribution of the transfer entropy estimate under the null hypothesis of no information flow which can be used to test for statistical significance. We also propose to use the bootstrapped distribution to estimate the bias 
which is due to finite sample effects and define Equation (8) as

$$
\mathrm{ET}_{\mathrm{J} \rightarrow \mathrm{I}}^{\mathrm{boot}}(k, l):=\mathrm{T}_{\mathrm{J} \rightarrow \mathrm{I}}(k, l)-\mathrm{T}_{\mathrm{J}_{\mathrm{boot}} \rightarrow \mathrm{I}}(k, l)
$$

where $\mathrm{T}_{\mathrm{J}_{\mathrm{boot}} \rightarrow \mathrm{I}}$ indicates the average over the estimates derived from the null bootstrap outlined above.

Note again the difference between the shuffled version and our bootstrapping approach: when shuffling the series, single symbols will be randomly rearranged into blocks that might not even occur in the actual sample. In our bootstrap the symbols will be rearranged based on the probabilities with which they occur in the actual sample. Thereby we expect to derive a better estimate for the finite sample bias since the joint probabilities of specific blocks of length $k$ that have to be estimated within the series $J$ correspond more closely to those that are observed in the actual sample.

To compare these two approaches we conduct a simulation study. First, we simulate two independent white noise processes $x$ and $y$. For each of the 499 simulation runs we create a time series of 7.000 observations which are then discretized according to Equation (6) using $q_{1}=\left(1-q_{2}\right)=0.1$. Due to independence of the data series, both the shuffling as well as our proposed bootstrap procedure should report estimates close to zero. Only in small samples the bias should be revealed. Therefore, we use subsamples of length 1.000, 2.000, etc up to 7.000 and conduct the bootstrap on these subsamples. The result is depicted in the left graph of Figure 1. Gray and black distinguish the directions from $x$ to $y$ and vice versa. As can be seen, the biased transfer entropy estimate (dotted line) only slowly goes to zero. Both shuffling (solid line) and bootstrapping (dashed line) efficiently capture the bias such that the corrected transfer entropy estimates are both close to zero. If we introduce some dependence in the individual time series while still keeping them independent, the result holds that both shuffling and bootstrapping provide a reliable bias correction.

Insert Figure 1 about here

The gains of the proposed bootstrapping become apparent when the data are 
not independent. We therefore simulate between 200 and 100.000 observations of the following model

$$
\begin{array}{r}
x_{t}=0.2 x_{t-1}+\varepsilon_{x, t} \\
y_{t}=x_{t-1}+\varepsilon_{y, t}
\end{array}
$$

with $\varepsilon_{i, t} \sim N(0,2)$. In this case, knowing $x_{t-1}$ helps to predict $y_{t}$, but not vice versa. Obviously these data are cointegrated, but cointegration is not always confirmed by cointegration tests, in particular in the small samples. For the transfer entropy measures we expect significant information flow from $x$ to $y$ and none from $y$ to $x$. The flow from $x$ to $y$ is colored in gray, $y$ to $x$ in black. As can be seen, the shuffling, in particular in the smallest samples, overestimates the bias (the solid line depicting ET $^{\text {shuffed }}$ is below the dashed line which depicts ET $^{\text {bot }}$ ). The difference vanishes as the sample size grows, but the bias generally vanishes as well. We therefore conclude that our bootstrapping procedure outperforms the estimation of the bias through shuffling in small samples.

In order to derive the distribution of the transfer entropy estimates themselves, we need to alter the proposed bootstrap procedure, since we have to preserve the dependencies between both time series. Consequently, we conduct the following steps: we first collapse and recode the two time series and define the block length $k$ of the collapsed time series according to the mutual information criterion in Equation (7). Then, the transition probabilities of the implied Markov process are estimated and used to produce replications of the collapsed time series. In a last step the two time series are disentangled from the simulated (collapsed) time series and transfer entropy is estimated. Repeating these steps yields the bootstrapped distribution of the transfer entropy estimates and in particular their standard errors can be derived.

A further issue that has to be considered is the discretization of the data. In most empirical applications the data - even if already discrete - have to be further discretized to reduce the number of possible states. The difficulties of discretizing the data and determining the partitions is referred to as the generating partitions 
problem. There exist different methods for discretization of the data as well as for estimation of the joint and conditional probabilities in Equation (5) (see for instance Hlavackova-Schindler, Palus, Vejmelka, and Bhattacharya, 2007). In the following applications we will use a simple partitioning of the data into three disjoint bins (symbolic encoding) which is motivated by economic considerations (see Section 4.1). Joint and conditional probabilities are approximated by the observed frequencies.

\section{Empirical Applications}

\subsection{Information flows between the CDS market and the corporate bond mar- ket}

With the emergence of the Credit Default Swap (CDS) market, default risk has become directly tradable in the over-the-counter (OTC) market: a CDS is a contract between two counterparties which transfers credit risk from the protection buyer to the protection seller who is willing to assume the risk for a pre-specified fee. In case of default of the underlying financial instrument the buyer receives a payoff. The CDS spread or premia is denoted in basis points and gives the annualized fee of the notional volume.

The CDS market is linked to the corporate bond market, as the difference between a risky bond yield and the risk-free rate also determines the credit risk associated with a specific company. Consequently, as both markets price credit risk, there exists an approximate arbitrage relation between the CDS and the corporate bond market (see Duffie, 1999, Hull and White, 2000a,b).

This arbitrage relation can be explained as follows. Suppose an investor buys a $T$-year par bond with yield to maturity of $y$ issued by the reference entity. The investor also buys credit protection on that entity for $T$ years at $p_{C D S}$. The net annual return is $y-p_{C D S}$ which, by arbitrage, and because default risk is eliminated, should be equal to the $T$-year risk-free rate denoted by $x$. If $y-p_{C D S}<x$, then shorting the risky bond, writing protection on the CDS market, and buying the risk free rate would present an arbitrage opportunity. If $y-p_{C D S}>x$, then buying the 
risky bond and protection, and shorting the risk-free bond becomes profitable. Accordingly, the price of the CDS should equal the credit spread, $p_{C D S}=p_{C S}=y-x$. However, with market imperfections such as liquidity premia, not exactly matching maturity dates, and cheapest to delivery options in case of default, the arbitrage relation is not perfect. Assuming cointegration accounts for the approximate nature of the arbitrage relation between CDS price and credit spread.

Most empirical studies that examine the importance of the CDS and bond market use a VECM framework and apply the Hasbrouck (1995) information shares (see Blanco et al. (2005), Grammig and Peter (forthcoming) and Dötz (2007)). However, these studies also note that due to market imperfections cointegration is not always supported by the data and a VECM might not suit the observed time series. Consequently, we propose to apply transfer entropy as an alternative, modelfree approach. The advantage of this methodology over Hasbrouck (1995) information shares is that it does not rely on a cointegration relationship to exist. Still, it is also applicable if the data are indeed cointegrated. The only requirement to apply transfer entropy is that the data have to be stationary which is achieved by taking first differences. Transfer entropy is therefore still valid even if the Hasbrouck (1995) assumptions are violated and, thus, can be applied much more flexibly.

Our data comprise 27 iTraxx companies and range from January 1, 2004 to December 31, 2011 (2085 observations). The time series of CDS premia are obtained from Datastream. We use 5-year contracts as they are most liquid (compare Blanco et al., 2005, Dötz, 2007). In order to calculate the corresponding bond spreads, we have to construct a time series of bond yields that matches the constant 5-years maturity of the CDS time series. We follow Blanco et al. (2005) and use linear interpolation: for each reference entity, we select in general a bond with less than five years to maturity and another one with more than five years to maturity. In some cases when only bonds with longer or shorter time to maturity are available (on some subinterval of the whole eight years), we choose the two bonds which are closest to five years to maturity. We then linearly interpolate these bond yields obtaining a yield curve for different maturities which is in turn used to predict the yield of an artificial bond with five years to maturity. This procedure is repeated for 
all trading days in the sample, thus generating a time series of bond yields for a five years to maturity bond. In order to avoid measurement errors due to various options in bonds, we only include bonds with fixed rate, which are not callable, puttable or convertible (see also Zhu, 2006). To eventually derive the bond spread (also referred to as credit spread), we calculate the difference between the risky bond yields and the risk-free interest rate. The latter is proxied by the 5 -year swap rates ${ }^{2}$. The bond data as well as the swap rates are obtained from Bloomberg.

As our sample period is rather long, the existing bond market data did not allow for linear interpolation over the whole sample period for the majority of the 125 iTraxx companies as we need at least two bonds at any point in time of the observation period. We therefore had to restrict our sample to 27 reference entities for which data over the whole sample period are available. Note that the selection of these reference entities is not based on specific criteria, but fully due to the availability of data. Table 1 provides information (ticker symbol, country of origin and operating sector) on the reference entities used in this study.

\section{Insert Table 1 about here}

In order to derive the transfer entropy estimates, we calculate first differences of CDS prices $r_{t}^{C D S}=p_{t}^{C D S}-p_{t-1}^{C D S}$ and the corresponding credit spreads (CS) $r_{t}^{C S}=p_{t}^{C S}-p_{t-1}^{C S}$ to ensure stationarity. The observations are then partitioned into discretized values according to Equation (6). We choose the 0.05 quantile of either series for $q_{1}$ and the 0.95 quantile for $q_{2}{ }^{3}$ The first bin corresponds to extremely large negative changes, the second to intermediate and the third to extremely large changes in the CDS prices and the credit spread. This choice is motivated by the leptokurtic distribution of changes in CDS prices and credit spreads.

Insert Figure 2 about here

\footnotetext{
${ }^{2}$ In several studies, government bond yields are used to proxy the risk-free rate. However, empirical evidence is mostly in favor of the swap rate as an appropriate proxy for the risk-free rate (see Blanco et al., 2005, Hull, Predescu, and White, 2004, Zhu, 2006).

${ }^{3}$ Using the values of the 0.1 quantile and 0.9 quantile as cut-off points does not qualitatively change the overall results, in particular the estimates remain still significant at least on a $5 \%$ significance level. When the observations in the second bin are further reduced, however, transfer entropy estimates become mostly insignificant.
} 
As can be seen from Figure 2 the data deviate from a normal distribution and reveal fat tails and a peaked center. Within the context of price discovery or information transfer in general the main task is to determine which market contributes first and the most to a common information set. If a market is informationally dominant, extreme changes in this market should be incorporated subsequently into the other market's prices. The observations in the tails of the leptokurtic return distributions of CDS prices and bond spreads therefore are of major interest. Since the time series are likely to contain a considerable amount of noise due to the illiquidity of the bond market and the OTC trading of both assets, the intermediate bin is kept rather large. Thereby, we seek to identify extreme, informative changes more clearly.

For each reference entity we select the block lengths based on the conditional mutual information criteria (see Equation (7)). The estimated block length varies between $k=l=1$ and $k=l=5 .{ }^{4}$

Table 2 presents the effective transfer entropy estimates $\mathrm{ET}^{\text {boot }}$ which are calculated according to Equation (9). Column 2 holds the estimates of information flow from the CDS to the bond market, column 3 from the bond to the CDS market. Column 4 gives the difference between the estimates.

\section{Insert Table 2 about here}

The effective transfer entropy estimates are statistically significant at conventional levels for all reference entities. This indicates bi-directional information transfer between the CDS and bond market. Considering the difference between the estimates in the last column in Table 2, we observe a larger information flow from the CDS market to the bond market for 19 reference entities. For the remaining 8 reference entities the information flow from the bond market to the CDS market dominates. However, the difference between information flows is only statistically significant for BMW and VOW where dominance of the CDS market is indicated. Even though our results are weaker, they point towards the same conclusions as Blanco et al. (2005) or Grammig and Peter (forthcoming) who, based on VECM,

\footnotetext{
${ }^{4}$ Detailed results are available upon request.
} 
state that the CDS market is the informational dominant market. However, these studies use a different sample of reference entities including US listed corporations. They also select only those reference entities for estimation, for which the data supports a cointegration relation. Norden and Weber (2009) also examine US and European firms and conclude that the relative importance of the CDS market is less pronounced for European firms than for US firms. Our results point into the same direction: for our European reference entities, transfer entropy estimates stress the importance of both the CDS and the bond market with regard to information transfer.

One of the key factors of the recent financial crisis was the deterioration of the CDS market. As our sample includes this period of time, we examine the effect of the financial crisis on the information transfer between the CDS and the bond market. As our full-length sample is rather long, we are able to partition the data into three phases. Phase 1 (1/1/2004-6/30/2007) denotes the pre-crisis period, phase $2(7 / 1 / 2007-9 / 30 / 2009)$ the crisis and phase $3(10 / 1 / 2009-12 / 31 / 2011)$ the post-crisis period. We are aware that there is no exact date associated with the start and end of the crisis. We follow Bai and Collin-Dufresne (2011) with this definition and also consider the evolution of the CDS premia and bond spreads as shown for an exemplary reference entity (BASF) in Figure 3 for which we observe a sharp increase in both series between 2007 and 2009. In addition, as transfer entropy estimates are based on transition probabilities derived from observed frequencies in the sample, we avoid phases which are too short in order to keep the estimates reliable across the three phases.

\section{Insert Figure 3 about here}

The results are given in Table 3 . In phase 1 we overall observe less information transmission between both markets. Effective transfer entropy estimates are statistically significant into both directions for only six reference entities. For nine we observe significant information transmission in one direction, for four reference entities from the bond to the CDS market and for five reference entities from the CDS to the bond market. The informational link between both markets then 
increases during the crisis period (phase 2). Effective transfer entropy estimates indicate statistically significant bi-directional information flows for the majority (23 out of 27) of reference entities. The information flow from the CDS market exceeds the information flow from the bond market for 16 reference entities. Phase 3 shows a similar picture; effective transfer entropy estimates are significant for all but one reference entity (EDF) and for eleven companies the information flow from the CDS market exceeds the flow originating in the bond market. Overall, the results show that information transmission between the CDS and bond market increased over time and the importance of CDS market was highest during the crisis period. This is similar to the results of a study by Coudert and Gex (2010) who find that for sovereigns the CDS market leads the bond market especially during the period of the recent crisis.

\subsection{Information transfer between market risk and credit risk}

With respect to the process of pricing credit risk, we have shown that the CDS market plays an important role. Yet, when agents price CDS, they need information concerning credit risk, i.e the default probability of the underlying reference entity. Some information might be gained from rating agencies. Still, the question remains whether information concerning credit risk can also be extracted from the stock market. A theoretical link between stock market and credit risk can be found in the model by Merton (1974). Empirical studies also document this link. Byström (2005) examines the relation between the iTraxx indices as a measure for credit risk and the stock price movements of the underlying entities. He detects a positive correlation between stock index return volatility and the iTraxx. Furthermore, Longstaff, Pan, Lasse, and Singleton (2011), Collin-Dufresne, Goldstein, and Spencer (2001) as well as Pan and Singleton (2008) find a link between sovereign credit risk and volatility indices. Figuerola-Ferrett and Paraskevopoulos (2009) also examine the dynamic link between market risk and credit risk. Using time series data before and throughout the recent crisis, they find a cointegration relationship between CDS premia and the VIX and estimate price discovery measures based on a VECM. 
In the following, we use the concept of transfer entropy to determine the dynamic link between market risk and credit risk by quantification of the information transfer between the iTraxx and the VIX Index. The VIX is used as a proxy for market risk as high VIX values are generally associated with a large amount of volatility in the stock market as a result of investor uncertainty. It is based on the implied volatilities of S\&P 500 index options and measures the expectations of stock market volatility over the next 30 days ${ }^{5}$.

The data comprise daily closing prices of the VIX ranging from March 21, 2005 to November 23, 2011 and the corresponding iTraxx Europe 5-year index data, i.e. we have 1685 observations $^{6}$. Figure 5 shows the time series of VIX and iTraxx over the sampling period.

Insert Figure 5 about here

After computing first differences in both series the observations are selected into three bins as in Equation (6) and effective transfer entropy measures are estimated for both directions according to Equation (8). The number of lags included was selected by the mutual information criterion (see Equation (7)). Furthermore, the thresholds for selection into the three bins are varied. Figure 4 shows Kernel density plots for VIX and iTraxx first differences. We can see that compared to the distribution of the CDS premia and credit spread in the first application, the tails of the distribution are much more pronounced. These tail observations are those that we want to catch in the first and third bin as they are supposed to be most informative. Still, it is less evident to determine the appropriate size of the central bin than in the CDS credit spread case. Therefore, we will vary the size of the second bin in order to examine the effect on the resulting transfer entropy estimates in more detail. To remain consistent with the economic reasoning above, we restrict the

\footnotetext{
${ }^{5}$ First constructed from the CBOE S\&P 100 index option prices, the VIX was introduced in 1993. In 2003 the construction of the VIX was revised and the underlying index has been changed to the CBOE S\&P 500 index (see Whaley, 2009).

${ }^{6}$ The iTraxx Europe is a CDS index which is composed of the 125 most liquid CDS referencing European investment grade credits. The index resulted from a 2004 merger of the two main CDS indices iBoxx and Trac-c and is traded over-the-counter, mostly with five years maturity.
} 
binning in such a way that the second (central) bin has to remain larger than the tail bins.

\section{Insert Figure 4 about here}

The results are presented in Table 4. Overall, we observe a larger information flow from the VIX to the iTraxx. Effective transfer entropy estimates are statistically significant for three out of five of the different definitions of bins. In three cases, the estimate of the bias became larger than the estimate of transfer entropy, resulting in negative values of the effective transfer entropy (irrespective of using shuffling or bootstrapping for bias correction). This result is closely linked to the choice of the number of lags. Note that the mutual information criterion did not select the same block length for all binnings. The longer the blocks, the more transition probabilities are to be estimated from the sample, increasing the variance of the estimates and possibly reducing their statistical significance. This noise also leads to high estimates of the bias which may then render effective transfer entropy negative. Still, our results are generally in line with Figuerola-Ferrett and Paraskevopoulos (2009) who find that the VIX is informationally dominant compared to the iTraxx. Even though the difference between the effective transfer entropy estimates for our sample is only statistically significant in one case, we find consistently larger estimates for the information flow from the VIX to the iTraxx than vice versa. This result is robust across different binnings as long as the first and third bin are restricted to the tails of the distribution.

Insert Table 4 about here

As the time series of VIX and iTraxx also include the recent crisis period, we divide the data into the three phases as defined above to examine the effect of the crisis period. Results are provided in Table 5.

\section{Insert Table 5 about here}

In the pre-crisis period, our results point towards bi-directional information flow. In the first binning, both directions are significant with the iTraxx dominating 
the VIX. The difference is, however, not statistically significant. In the second binning, the picture is reversed: we find significantly higher transfer entropy estimates for the information flow from the VIX to the iTraxx. For the remaining binnings the transfer entropy measure picks up too much noise and therefore the bias estimates become larger than the estimator for the transfer entropy itself. This is due to the comparatively high number of lags that the mutual information criterion suggested. During the crisis period, the importance of the VIX becomes more explicit: the effective transfer entropy from the VIX to the iTraxx is (highly) significant for three binnings. In the other direction, it is only significant (but still smaller) in the first binning. In some of the other binnings the noise component seems to dominate again and transfer entropy estimates become negative which means that there is no information flow from the iTraxx to the VIX, highlighting again the predominance of the VIX during this period. After the crisis, the dominance of the VIX still holds, but in general our results suggest that the market environment returns to bi-directional information flow. We find significant effective transfer entropy estimates in both directions, even though not throughout all binnings.

From the results presented above we conclude that a dynamic relation between market risk and credit risk exists with a predominant information transfer from the VIX to the iTraxx. One should bear in mind that the two market designs are different: the iTraxx is traded over-the-counter while the VIX is calculated on a fixed time scale. The information flow from VIX to the iTraxx might therefore be caused by other (macroeconomic) factors which are incorporated into the VIX first, while the non-electronic OTC trading of the iTraxx might induce a delay of incorporation of information. As our analysis is carried out on daily data, this issue should, however, be only of minor importance and not becloud our general conclusions. Further research might be conducted regarding this point, since when calculating transfer entropy, it is generally possible to condition on further variables to purge the resulting information flows of the common reaction to an external factor. However, an additional variable further increases the number of transition probabilities that have to be estimated from the sample, which requires more observations in order to yield results of some accuracy. Furthermore, the partitioning of the obser- 
vations into the different bins seems to be of importance and should be taken into consideration when interpreting transfer entropy estimates.

\section{Conclusion}

The paper uses the concept of transfer entropy to examine the information transfer between financial markets. Transfer entropy as defined by Schreiber (2000) quantifies information transmission based on the Kullback-Leibler distance. Its main advantages are that it is non-parametric and accounts for linear as well as non-linear dynamics. Thereby, it constitutes an interesting alternative to standard measures such as Granger causality, which can detect but not quantify the amount of information transfer. The bootstrap procedure proposed in this paper allows to conduct inference of the transfer entropy estimates, an issue that has not been addressed so far. By bootstrapping the underlying Markov process rather than shuffling the data or relying on block bootstraps we are able to test for statistical significance of the transfer entropy estimates more accurately. The same method is used to correct the bias in the transfer entropy estimates. It is shown that this method has favorable properties as compared to the standard, shuffling procedure.

The standard methodology to measure information transmission between financial markets is the information share technique of Hasbrouck (1995) which relies on the existence of a cointegration relationship. In the absence of cointegration, transfer entropy offers an appealing alternative to detect and quantify information flows. Even if cointegration is supported, but the information share bounds are very large, transfer entropy may be used as a further back-check to determine the informationally dominant market.

We apply the concept of transfer entropy to examine the information flows between the CDS and bond market using data on 27 iTraxx companies. The results show that even though information flows in both directions, the CDS market dominates the market for credit risk. By analyzing different time periods, we show that information transmission between the CDS and bond market increased over time and the importance of CDS market was highest during the crisis period. Our general 
results are therefore in line with previous studies by Blanco et al. (2005), Grammig and Peter (forthcoming) and Dötz (2007) which emphasize the dominance of the CDS market in pricing credit risk.

Furthermore, we examine the information transmission between market risk and credit risk as proxied by the VIX and the iTraxx Europe index. We find that information flows mainly from the VIX to the iTraxx. Before the recent financial crisis, information flow was probably bi-directional, but during the crisis period the importance of the VIX became apparent which constitutes an interesting result concerning the evaluation of credit risk. 


\section{References}

Baek, K. S., W.-S. Jung, O. Kwon, and H.-T. Moon (2005): “Transfer entropy analysis of the stock market," ArXiv Physics e-prints.

Bai, J. and P. Collin-Dufresne (2011): "The CDS-bond basis during the financial crisis of 2007-2009," Working Paper.

Blanco, R., S. Brennan, and I. W. Marsh (2005): "An empirical analysis of the dynamic relation between investment-grade bonds and credit default swaps," Journal of Finance, 60, 2255-2281.

Byström, H. (2005): “Credit default swaps and equity prices: the iTraxx CDS index market," Working Paper, Lund University.

Carlstein, E. (1986): "The use of subseries values for estimating the variance of a general statistic from a stationary sequence," The Annals of Statistics, 14, 11711179.

Collin-Dufresne, P., R. S. Goldstein, and M. Spencer (2001): “The determinants of credit spread changes," Journal of Finance, 56, 2177-2207.

Coudert, V. and M. Gex (2010): “The credit default swap market and the settlement of large defaults," CEPII, WP No 2010-17.

Dötz, N. (2007): "Time-varying contributions by the corporate bond and CDS markets to credit risk price discovery," Discussion Paper Series 2: Banking and Financial Studies,Deutsche Bundesbank, Research Centre.

Duffie, D. (1999): “Credit swap valuation,” Financial Analysts Journal, 55, 73-87.

Figuerola-Ferrett, I. and I. Paraskevopoulos (2009): “The dynamic relation between CDS markets and the VIX index," Working paper.

Fraser, A. M. and H. L. Swinney (1986): "Independent coordinates for strange attractors from mutual information," Phys. Rev. A, 33, 1134-1140.

Grammig, J. and F. J. Peter (forthcoming): "Tell-tale tails: A new approach to estimating unique market information shares," Journal of Financial and Quantitative Analysis.

Granger, C. W. J. (1969): "Investigating causal relations by econometric models and cross-spectral methods," Econometrica, 37, 424-438. 
Hartley, R. V. (1928): “Transmission of information,” Bell System Technical Journal, 535-563.

Hasbrouck, J. (1995): "One security, many markets: determining the contributions to price discovery," Journal of Finance, 50, 1175-1199.

Hlavackova-Schindler, K., M. Palus, M. Vejmelka, and J. Bhattacharya (2007): "Causality detection based on information-theoretic approaches in time series analysis," Physics report, 441, 1-46.

Horowitz, J. L. (2003): "Bootstrap methods for markov processes," Econometrica, $71,1049-1082$.

Hull, J., M. Predescu, and A. White (2004): "The relationship between credit default swap spreads, bond yields, and credit rating announcements," Journal of Banking and Finance, 28, 2789-2811.

Hull, J. C. and A. White (2000a): "Valuing credit default swaps I: No counterparty default risk," Journal of Derivatives, 8, 29-40.

Hull, J. C. and A. White (2000b): "Valuing credit default swaps II: Modeling default correlations," Journal of Derivatives, 8, 12-22.

Kullback, S. and R. A. Leibler (1951): "On information and sufficiency," The Annals of Mathematical Statistics, 1, 79-86.

Kwon, O. and J.-S. Yang (2008a): "Information flow between composite stock index and individual stocks," Physica A: Statistical Mechanics and its Applications, 387, 2851-2856.

Kwon, O. and J.-S. Yang (2008b): "Information flow between stock indices," EPL (Europhysics Letters), 82, 68003.

Lahiri, S. (1999): "Theoretical comparison of block bootstrap methods," The Annals of Statistics, 27, 386-404.

Longstaff, F., J. Pan, P. Lasse, and K. Singleton (2011): "How sovereign is sovereign credit risk?" American Economic Journal: Macroeconomics, 3, 75103.

Marschinski, R. and H. Kantz (2002): "Analysing the information flow between financial time series," The European Physical Journal B, 30, 275-281. 
Merton, R. (1974): “On the pricing of corporate debt: the risk structure of interest rates," Journal of Finance, 29, 449-470.

Norden, L. and M. Weber (2009): “The co-movement of credit deafault swap, bond and stock markets: an empirical anaylsis," European Financial Management, 15, $529-562$.

Pan, J. and K. Singleton (2008): "Default and recovery implicit in the term structure of sovereign CDS spreads," The Journal of Finance, 63, 2345-2384.

Papana, A., D. Kugiumtzis, and P. G. Larsson (2001): "Reducing the bias of causality measures," Physical Review E, 83.

Reddy, Y. V. and A. Sebastin (2009): "Are commodity and stock markets independent of each other? A case study in India," Journal of Alternative Investments, 11, 85-99.

Schreiber, T. (2000): "Measuring information transfer," Physical review letters, 85, 461-464.

Shannon, C. E. (1948): “A mathematical theory of communication,” Bell System Technical Journal, 27, 379-423.

Whaley, R. (2009): "Understanding the VIX," The Journal of Portfolio Management, 35, 98-105.

Zhu, H. (2006): "An empirical comparison of credit spreads between the bond market and the credit default swap market," Journal of Financial Services Research, 29, 211-235. 

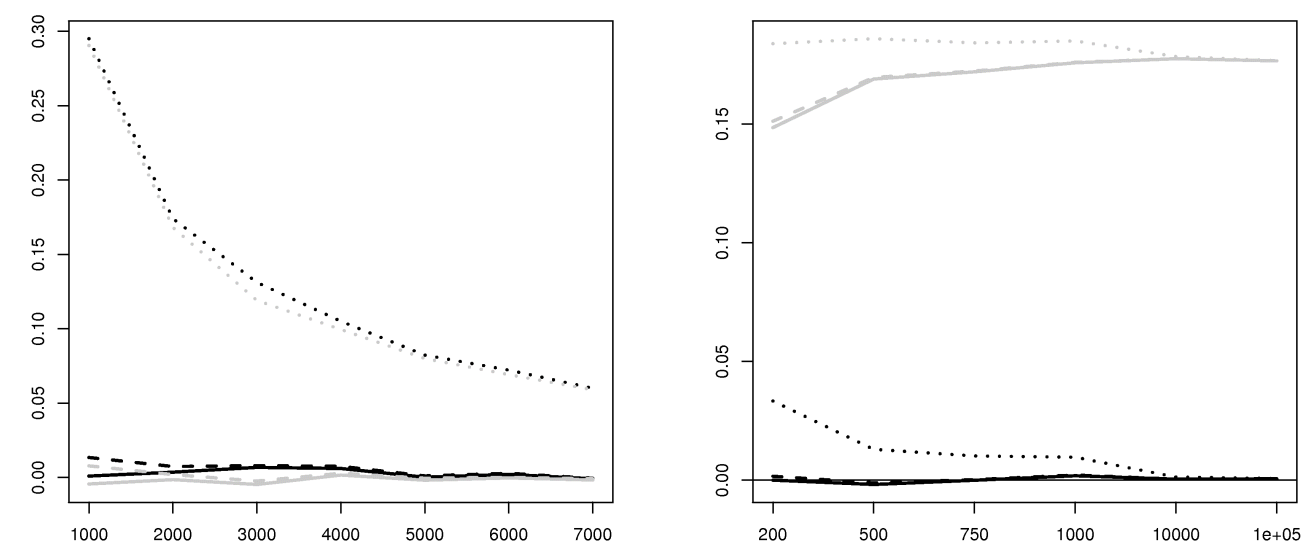

Figure 1: Illustration of small sample bias.

The figure depicts the (biased) transfer entropy estimate (dotted line) due to small sample size along with the bias corrected measures based on shuffling (solid line) and bootstrap (dashed line). Gray and black distinguish the two directions of information flow. The left graph refers to two independent white noise series, the right graph to a situation where one time series is the lag of the other plus noise. Scaling of the abscissa denotes the sample size used in the simulation runs. 

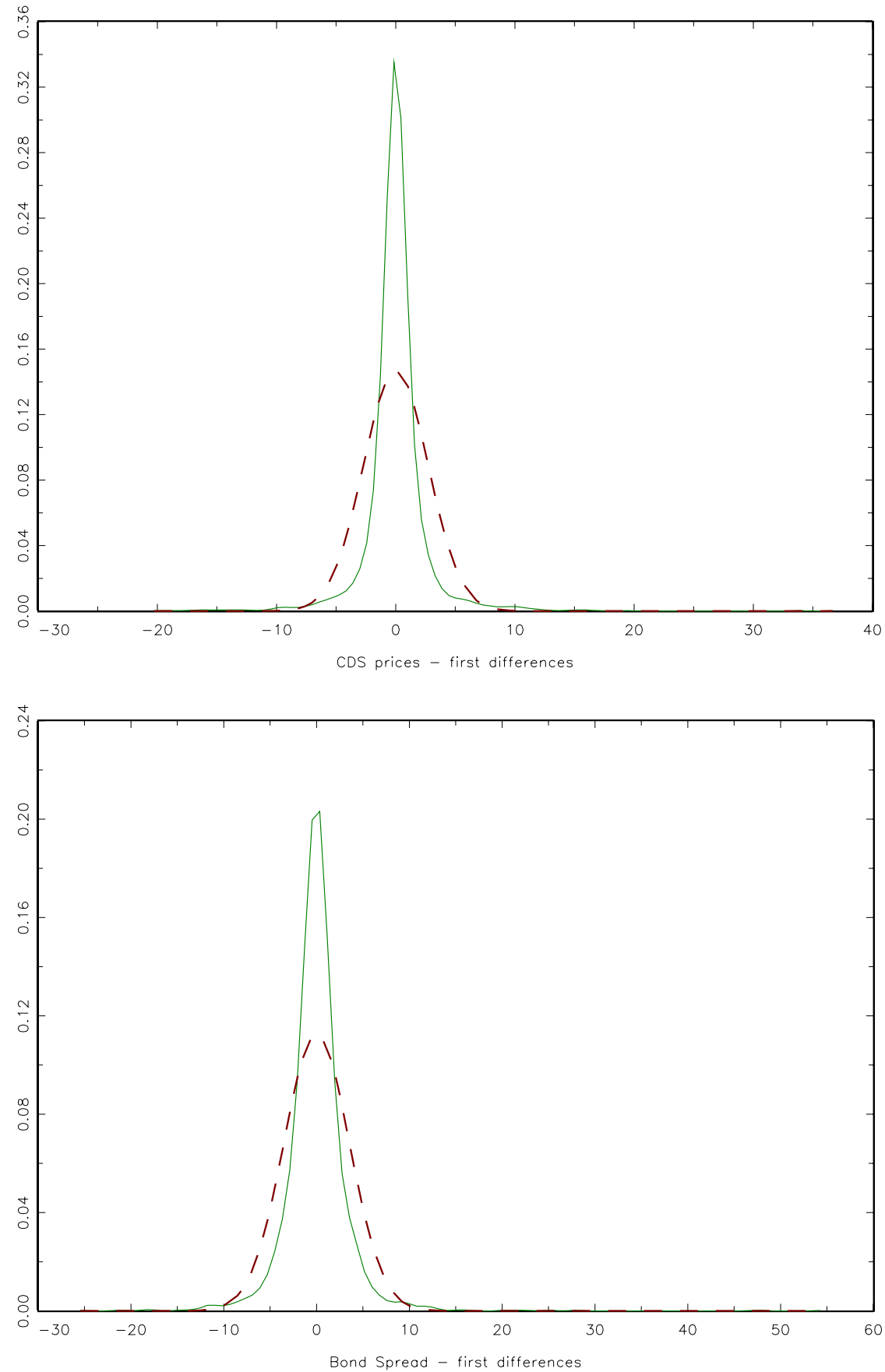

Figure 2: Kernel density plots of BASF CDS and credit spread first differences. The figure shows kernel density plots of CDS and credit spread (CS) first differences (solid line) for BASF together with the normal density (dashed line). 


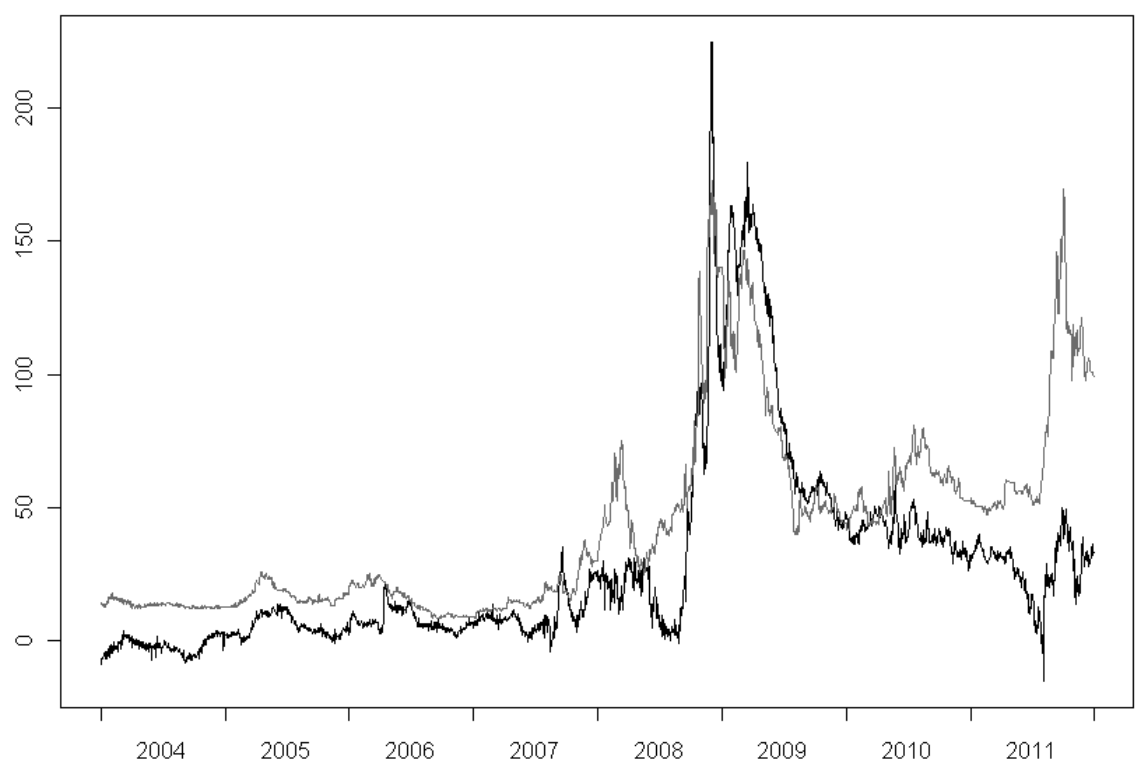

Figure 3: Credit spread and CDS premia for BASF

The graphic depicts time series of the credit spread (black line) and the CDS (grey line) premia for BASF, denoted in basis points. 

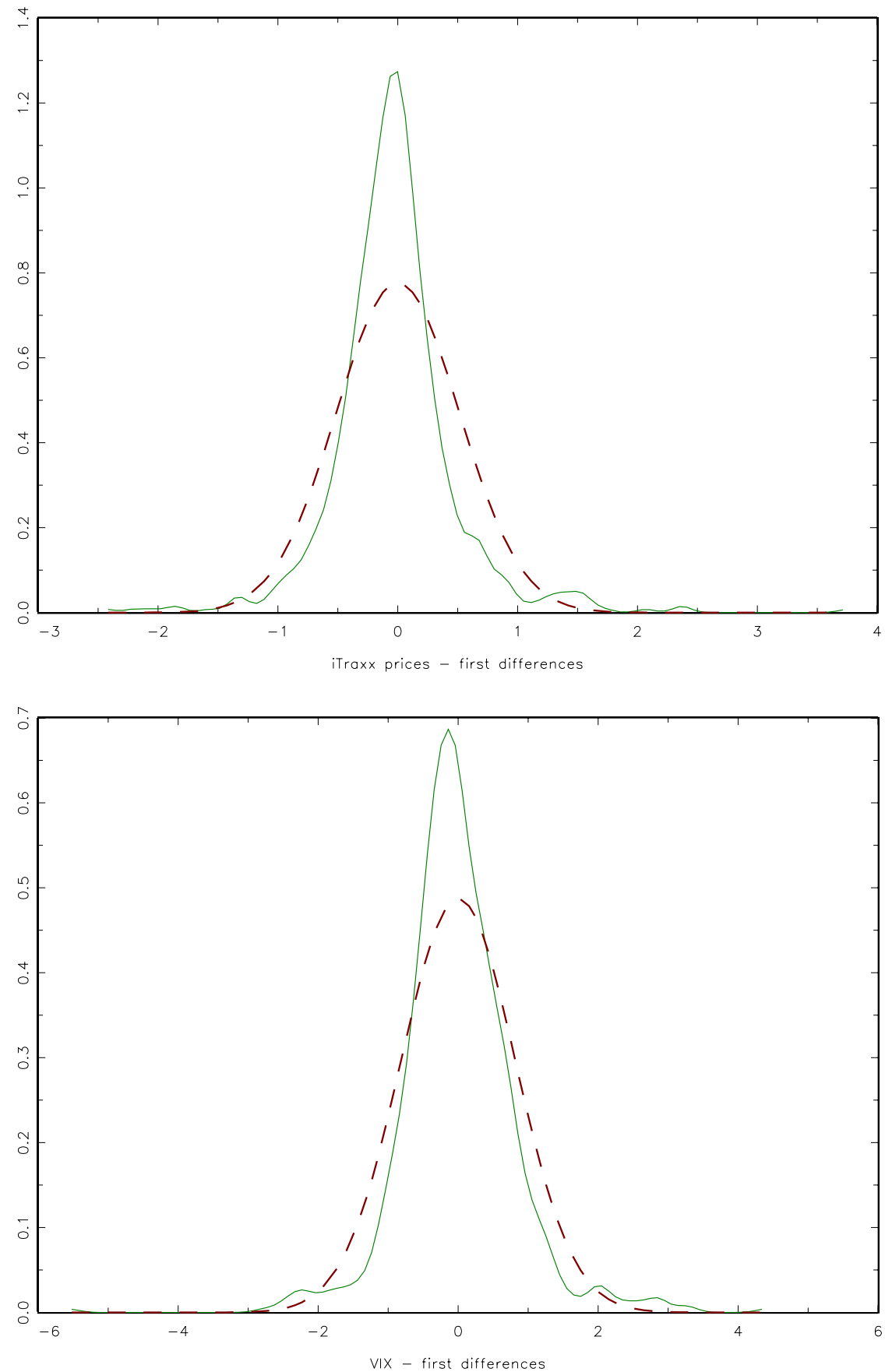

Figure 4: Kernel Density plots of iTraxx and credit VIX first differences.

The figure shows kernel density plots of the iTraxx and VIX first differences (solid line) together with the normal density (dashed line). 


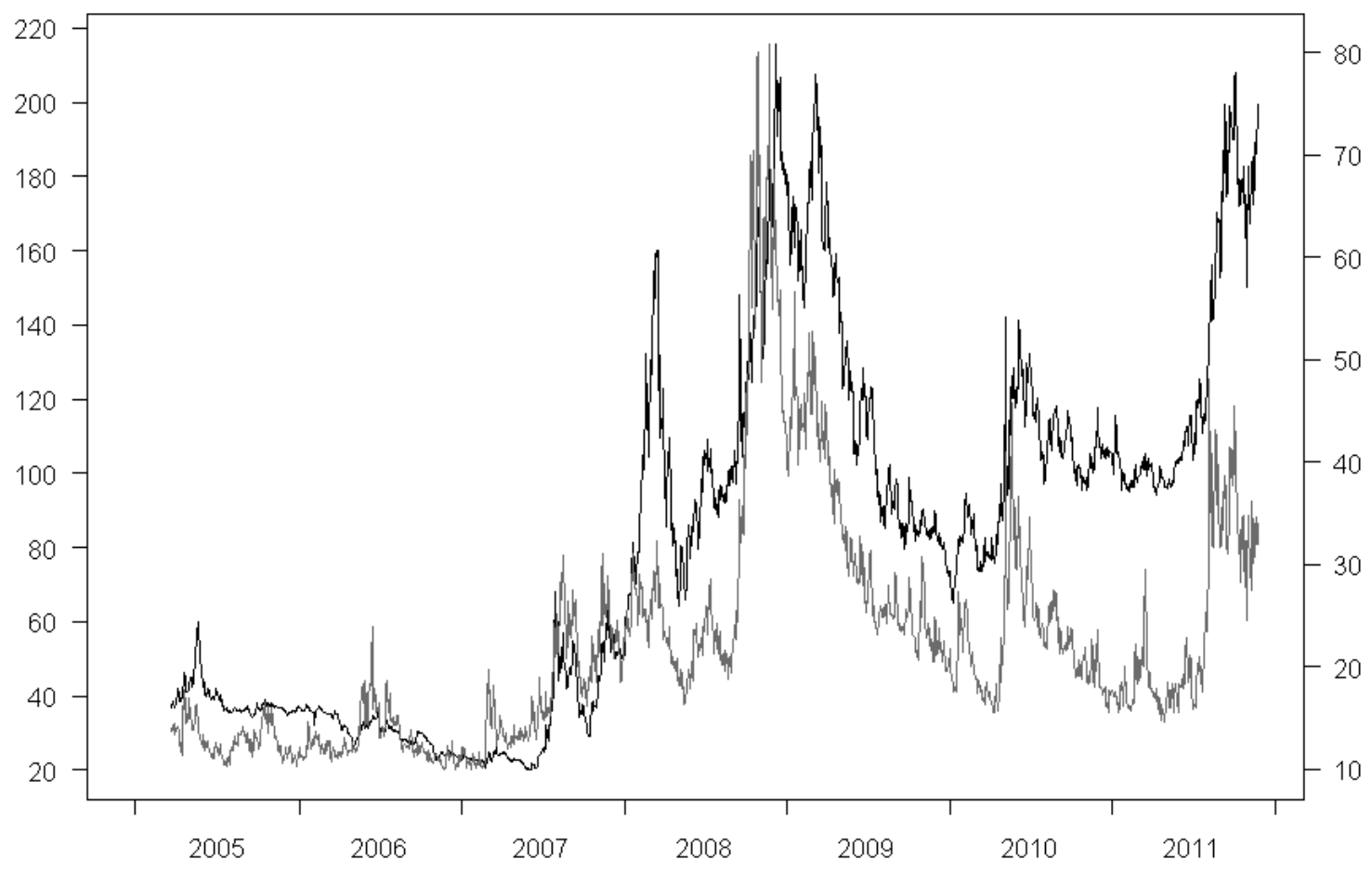

Figure 5: VIX and iTraxx.

The figure shows the VIX (grey line) and iTraxx (black line) time series. The left axis scale belongs to the iTraxx and is denoted in basis points. The right axis scale measures the VIX given in percent. 


\begin{tabular}{llll}
\hline Ticker & Company & Country & Sector \\
\hline AZ & Allianz & Germany & Financial \\
BASF & BASF & Germany & Industrials \\
BAY & Bayer & Germany & Industrials \\
BMW & BMW & Germany & Automobiles \\
CAR & Carrefour & France & Consumers \\
DT & Deutsche Telekom & Germany & TMT \\
EDF & Electricite de France & France & Energy \\
E & Enel & Italy & Energy \\
FOT & Fortum Oyi & Finland & Energy \\
FTE & France Telecom & France & TMT \\
GDF & GDF Suez & France & Energy \\
IBE & Iberdrola & Spain & Energy \\
KPN & Koninklijke KPN & Netherlands & TMT \\
LVMH & LVMH & France & Consumers \\
MEO & Metro & Germany & Consumers \\
MT & ArcelorMittal & Luxembourg & Industrials \\
NGG & National Grid & UK & Energy \\
REP & Repsol & Spain & Energy \\
RWE & RWE & Germany & Energy \\
SGO & St Gobain & France & Industrials \\
SOL & Solvay & Belgium & Industrials \\
STD & Banco Santander Central Hispano & Spain & Financial \\
TEF & Telefonica & Spain & TMT \\
TIT & Telecom Italia & Italy & TMT \\
VAT & Vattenfall & Sweden & Energy \\
VE & Veolia & France & Energy \\
VOW & VW & Germany & Automobiles \\
\hline & & & \\
\hline
\end{tabular}

Table 1: Reference entities

The table shows the ticker symbol, company name, country of origin and industry sector for each of the 27 iTraxx companies used in this study. 


\begin{tabular}{|c|c|c|c|}
\hline Ticker & $\mathrm{ET}^{\text {boot }}(\mathrm{CDS} \rightarrow \mathrm{CS})$ & $\mathrm{ET}^{\mathrm{boot}}(\mathrm{CS} \rightarrow \mathrm{CDS})$ & DIFF \\
\hline $\mathrm{AZ}$ & $\begin{array}{l}0.0989 * * * \\
(0.0135)\end{array}$ & $\begin{array}{l}0.0966 * * * \\
(0.0138)\end{array}$ & 0.0023 \\
\hline BASF & $\begin{array}{l}0.0736 * * * \\
(0.0173)\end{array}$ & $\begin{array}{l}0.0514 * * * \\
(0.0168)\end{array}$ & 0.0222 \\
\hline BAY & $\begin{array}{l}0.0826 * * * \\
(0.0176)\end{array}$ & $\begin{array}{l}0.0794 * * * \\
(0.0170)\end{array}$ & 0.0032 \\
\hline BMW & $\begin{array}{l}0.1204 * * * \\
(0.0178)\end{array}$ & $\begin{array}{l}0.0889 * * * \\
(0.0163)\end{array}$ & $0.0315 * *$ \\
\hline CAR & $\begin{array}{l}0.0737 * * * \\
(0.0162)\end{array}$ & $\begin{array}{l}0.0603 * * * \\
(0.0160)\end{array}$ & 0.0134 \\
\hline DT & $\begin{array}{l}0.0382 * * * \\
(0.0078)\end{array}$ & $\begin{array}{l}0.0398 * * * \\
(0.0071)\end{array}$ & -0.0015 \\
\hline EDF & $\begin{array}{l}0.0378 * * * \\
(0.0078)\end{array}$ & $\begin{array}{l}0.0365 * * * \\
(0.0080)\end{array}$ & 0.0013 \\
\hline EN & $\begin{array}{l}0.0646 * * * \\
(0.0171)\end{array}$ & $\begin{array}{l}0.0694 * * * \\
(0.0156)\end{array}$ & -0.0049 \\
\hline FOT & $\begin{array}{l}0.0837 * * * \\
(0.0124)\end{array}$ & $\begin{array}{l}0.1006 * * * \\
(0.0142)\end{array}$ & -0.0169 \\
\hline FTE & $\begin{array}{l}0.0695 * * * \\
(0.0157)\end{array}$ & $\begin{array}{l}0.0787 * * * \\
(0.0156)\end{array}$ & -0.0092 \\
\hline GDF & $\begin{array}{l}0.0751 \text { *** } \\
(0.0163)\end{array}$ & $\begin{array}{l}0.0719 * * * \\
(0.0170)\end{array}$ & 0.0032 \\
\hline IBE & $\begin{array}{l}0.1072 * * * \\
(0.0173)\end{array}$ & $\begin{array}{l}0.0972 * * * \\
(0.0173)\end{array}$ & 0.0100 \\
\hline $\mathrm{KPN}$ & $\begin{array}{l}0.0324 * * * \\
(0.0068)\end{array}$ & $\begin{array}{l}0.0364 * * * \\
(0.0076)\end{array}$ & -0.0039 \\
\hline LVMH & $\begin{array}{l}0.1321 * * * \\
(0.0166)\end{array}$ & $\begin{array}{l}0.1151 * * * \\
(0.0171)\end{array}$ & 0.0170 \\
\hline MEO & $\begin{array}{l}0.0562 * * * \\
(0.0095)\end{array}$ & $\begin{array}{l}0.0517 * * * \\
(0.0108)\end{array}$ & 0.0046 \\
\hline MT & $\begin{array}{l}0.1160 * * * \\
(0.0173)\end{array}$ & $\begin{array}{l}0.1106 * * * \\
(0.0171)\end{array}$ & 0.0054 \\
\hline NGG & $\begin{array}{l}0.0580 * * * \\
(0.0090)\end{array}$ & $\begin{array}{l}0.0413 * * * \\
(0.0075)\end{array}$ & 0.0167 \\
\hline REP & $\begin{array}{l}0.1023 * * * \\
(0.0164)\end{array}$ & $\begin{array}{l}0.1032 * * * \\
(0.0171)\end{array}$ & -0.0009 \\
\hline RWE & $\begin{array}{l}0.0737 * * * \\
(0.0132)\end{array}$ & $\begin{array}{l}0.1000 * * * \\
(0.0145)\end{array}$ & -0.0263 \\
\hline $\mathrm{SGO}$ & $\begin{array}{l}0.0620 * * * \\
(0.0092)\end{array}$ & $\begin{array}{l}0.0557 * * * \\
(0.0095)\end{array}$ & 0.0064 \\
\hline SOL & $\begin{array}{l}0.0146 * * \\
(0.0078)\end{array}$ & $\begin{array}{l}0.0239 * * * \\
(0.0082)\end{array}$ & -0.0094 \\
\hline STD & $\begin{array}{l}0.0863 * * * \\
(0.0124)\end{array}$ & $\begin{array}{l}0.0780 * * * \\
(0.0120)\end{array}$ & 0.0083 \\
\hline TEF & $\begin{array}{l}0.1121 * * * \\
(0.0145)\end{array}$ & $\begin{array}{l}0.1046 * * * \\
(0.0146)\end{array}$ & 0.0075 \\
\hline TIT & $\begin{array}{l}0.0345 * * * \\
(0.0071)\end{array}$ & $\begin{array}{l}0.0201 * * * \\
(0.0061)\end{array}$ & 0.0144 \\
\hline VAT & $\begin{array}{l}0.0369 * * * \\
(0.0070)\end{array}$ & $\begin{array}{l}0.0369 * * * \\
(0.0073)\end{array}$ & 0.0000 \\
\hline VE & $\begin{array}{l}0.0451 * * * \\
(0.0076)\end{array}$ & $\begin{array}{l}0.0384 * * * \\
(0.0086)\end{array}$ & 0.0067 \\
\hline VOW & $\begin{array}{l}0.0627 * * * \\
(0.0084)\end{array}$ & $\begin{array}{l}0.0229 * * * \\
(0.0073)\end{array}$ & $0.0398 * *$ \\
\hline
\end{tabular}

Table 2: Effective transfer entropy estimates

The table shows effective transfer entropy estimates from the CDS to the bond market, $\mathrm{ET}(\mathrm{CDS} \rightarrow \mathrm{CS})$ and from the bond market to the CDS market, ET(CS $\rightarrow$ CDS). The last column gives the difference between both estimates, so that negative (positive) values indicate a larger information flow from the bond (CDS) to the CDS (bond) market. Standard errors derived from the bootstrap procedure outlined in Section 3 using 1000 simulation runs are given in parentheses.

$$
*, * * * * * \text { indicate significance at the } 10,5,1 \% \text { significance level. }
$$




\begin{tabular}{|c|c|c|c|c|c|c|}
\hline \multirow[b]{2}{*}{ Ticker } & \multicolumn{2}{|c|}{$\begin{array}{c}\text { PHASE 1 (PRE-CRISIS) } \\
\text { ET }^{\text {boot }}\end{array}$} & \multicolumn{2}{|c|}{$\begin{array}{c}\text { PHASE } 2 \text { (CRISIS) } \\
\text { ET }^{\text {boot }}\end{array}$} & \multicolumn{2}{|c|}{$\begin{array}{c}\text { PHASE } 3 \text { (POST-CRISIS) } \\
\text { ET }^{\text {boot }}\end{array}$} \\
\hline & $(\mathrm{CDS} \rightarrow \mathrm{CS})$ & $(\mathrm{CS} \rightarrow \mathrm{CDS})$ & $(\mathrm{CDS} \rightarrow \mathrm{CS})$ & $(\mathrm{CS} \rightarrow \mathrm{CDS})$ & $(\mathrm{CDS} \rightarrow \mathrm{CS})$ & $(\mathrm{CS} \rightarrow \mathrm{CDS})$ \\
\hline AZ & -0.0202 & $0.0416 * * *$ & $0.0704 * * *$ & $0.0408 * * *$ & $0.0348 * * *$ & $0.0479 * * *$ \\
\hline BASF & $\begin{array}{l}(0.0159) \\
0.0068\end{array}$ & $\begin{array}{c}(0.0190) \\
-0.0059\end{array}$ & $0.0931 * * *$ & $\stackrel{(0.0156)}{0.0806 * * *}$ & $\stackrel{(0.0159)}{0.0922 * * *}$ & $\stackrel{(0.0161)}{0.0996 * * *}$ \\
\hline BAY & $\begin{array}{l}(0.0073) \\
0.0226\end{array} * *$ & $\stackrel{(0.0067)}{0.0232} * *$ & $\stackrel{(0.0236)}{0.0689} * * *$ & $\stackrel{(0.0221)}{0.0638} * * *$ & $\stackrel{(0.0270)}{0.0258}$ & $\stackrel{(0.0257)}{0.0299} *$ \\
\hline BMW & $\begin{array}{l}\stackrel{(0.0118)}{0.0017} \\
(0.0078)\end{array}$ & $0.018 * *$ & $\begin{array}{l}(0.0198) \\
0.050 * * * \\
(0.0226)\end{array}$ & $\begin{array}{l}(0.0189) \\
0.030 * * * \\
(0.0172)\end{array}$ & $\begin{array}{l}(0.0291) \\
0.0238 * * * \\
(0.0163)\end{array}$ & $\begin{array}{l}(0.0312) \\
0.0282 * * * \\
(0.0164)\end{array}$ \\
\hline CAR & $\begin{array}{l}0.0218 \\
(0.0198)\end{array}$ & $\begin{array}{l}(0.0101) \\
0.0129 \\
(0.0187)\end{array}$ & $\begin{array}{l}(0.0226) \\
0.0826 * * * \\
(0.0224)\end{array}$ & $\begin{array}{l}0.0714 * * * \\
(0.0244)\end{array}$ & $\begin{array}{l}0.1132 * * * \\
(0.0296)\end{array}$ & $\begin{array}{l}0.1089 * * * \\
(0.0295)\end{array}$ \\
\hline DT & $\begin{array}{l}0.0317 * * \\
(0.0134)\end{array}$ & $\begin{array}{l}0.0139 \\
(0.0144)\end{array}$ & $\begin{array}{l}0.0089 * \\
(0.0122)\end{array}$ & $\begin{array}{l}-0.0019 \\
(0.0076)\end{array}$ & $\begin{array}{l}0.0742 * * * \\
(0.0225)\end{array}$ & $\begin{array}{l}0.0942 * * * \\
(0.0231)\end{array}$ \\
\hline EDF & $\begin{array}{l}0.0042 \\
(0.0111)\end{array}$ & $\begin{array}{l}0.0012 \\
(0.0102)\end{array}$ & $\begin{array}{l}0.0375 * * * \\
(0.0137)\end{array}$ & $\begin{array}{l}0.0333 \\
(0.0156)\end{array}$ & $\begin{array}{l}0.0216 \\
(0.0309)\end{array}$ & $\begin{array}{l}0.0152 \\
(0.0307)\end{array}$ \\
\hline $\mathrm{EN}$ & $\begin{array}{l}0.0089 \\
(0.0125)\end{array}$ & $\begin{array}{c}-0.0006 \\
(0.0117)\end{array}$ & $\begin{array}{l}0.0237 * \\
(0.0219)\end{array}$ & $\begin{array}{l}0.0186 \\
(0.0182)\end{array}$ & $\begin{array}{l}0.1086 * * * \\
(0.0249)\end{array}$ & $\begin{array}{l}0.0563 * * * \\
(0.0238)\end{array}$ \\
\hline FOT & $\begin{array}{l}0.0129 \\
(0.0162)\end{array}$ & $\begin{array}{l}0.012 \\
(0.0151)\end{array}$ & $\begin{array}{l}0.0449 \\
(0.0188)\end{array}$ & $\begin{array}{l}0.0467 * * * \\
(0.0173)\end{array}$ & $\begin{array}{l}0.0488 * * * \\
(0.0182)\end{array}$ & $\begin{array}{l}0.0714 * * * \\
(0.0202)\end{array}$ \\
\hline FTE & $\begin{array}{l}0.0478 * * * \\
(0.0184)\end{array}$ & $\begin{array}{l}0.0291 * * \\
(0.0185)\end{array}$ & $\begin{array}{l}0.0286 * * \\
(0.0146)\end{array}$ & $\begin{array}{l}0.0363 * * * \\
(0.0145)\end{array}$ & $\begin{array}{l}0.0913 * * * \\
(0.0254)\end{array}$ & $\begin{array}{l}0.0939 * * * \\
(0.0230)\end{array}$ \\
\hline GDF & $\begin{array}{l}0.0129 \\
(0.0087)\end{array}$ & $\begin{array}{l}0.0059 \\
(0.0093)\end{array}$ & $\begin{array}{l}0.026 * * * \\
(0.0166)\end{array}$ & $\begin{array}{l}0.0133 * * \\
(0.0139)\end{array}$ & $\begin{array}{l}0.0789 * * * \\
(0.0258)\end{array}$ & $\begin{array}{l}0.0688 * * * \\
(0.0221)\end{array}$ \\
\hline IBE & $\begin{array}{l}-0.0035 \\
(0.0065)\end{array}$ & $\begin{array}{l}0.0008 \\
(0.0083)\end{array}$ & $\begin{array}{l}0.0336 * * * \\
(0.0142)\end{array}$ & $\begin{array}{l}0.0433 * * * \\
(0.0152)\end{array}$ & $\begin{array}{l}0.0686 * * * \\
(0.0182)\end{array}$ & $\begin{array}{l}0.0356 * * * \\
(0.0140)\end{array}$ \\
\hline $\mathrm{KPN}$ & $\begin{array}{l}0.036 * * * \\
(0.0115)\end{array}$ & $\begin{array}{l}0.0371 * * * \\
(0.0114)\end{array}$ & $\begin{array}{l}0.0206 \\
(0.0235)\end{array}$ & $\begin{array}{l}0.0258 \\
(0.0233)\end{array}$ & $\begin{array}{l}0.0332 * * * \\
(0.0162)\end{array}$ & $\begin{array}{l}0.032 * * * \\
(0.0172)\end{array}$ \\
\hline LVMH & $\begin{array}{l}0.0123 \\
(0.0097)\end{array}$ & $\begin{array}{l}0.0314 * * * \\
(0.0115)\end{array}$ & $\begin{array}{l}0.1224 * * * \\
(0.0308)\end{array}$ & $\begin{array}{l}0.1033 * * * \\
(0.0300)\end{array}$ & $\begin{array}{l}0.0237 * * \\
(0.0119)\end{array}$ & $\begin{array}{l}0.0304 * * * \\
(0.0138)\end{array}$ \\
\hline MEO & $\begin{array}{l}0.0068 \\
(0.0213)\end{array}$ & $\begin{array}{l}0.0118 \\
(0.0218)\end{array}$ & $\begin{array}{l}0.0144 * * \\
(0.0140)\end{array}$ & $\begin{array}{l}0.0141 * * \\
(0.0139)\end{array}$ & $\begin{array}{l}0.0834 * * * \\
(0.0164)\end{array}$ & $\begin{array}{l}0.0707 * * * \\
(0.0232)\end{array}$ \\
\hline MT & $\begin{array}{l}0.0295 * * \\
(0.0135)\end{array}$ & $\begin{array}{l}0.0166 \\
(0.0129)\end{array}$ & $\begin{array}{l}0.0217 * * * \\
(0.0151)\end{array}$ & $\begin{array}{l}0.0109 * * \\
(0.0123)\end{array}$ & $\begin{array}{l}0.046 * * \\
(0.0296)\end{array}$ & $\begin{array}{l}0.0388 * * \\
(0.0262)\end{array}$ \\
\hline NGG & $\begin{array}{l}0.0066 \\
(0.0072)\end{array}$ & $\begin{array}{l}0.0084 \\
(0.0074)\end{array}$ & $\begin{array}{l}0.0484 * * * \\
(0.0145)\end{array}$ & $\begin{array}{l}0.045 * * * \\
(0.0173)\end{array}$ & $\begin{array}{l}0.0136 * \\
(0.0138)\end{array}$ & $\begin{array}{l}0.0233 * * \\
(0.0121)\end{array}$ \\
\hline REP & $\begin{array}{l}0.0181 * * \\
(0.0076)\end{array}$ & $\begin{array}{l}0.0147 * * \\
(0.0084)\end{array}$ & $\begin{array}{l}0.0268 \\
(0.0302)\end{array}$ & $\begin{array}{l}0.047 * * \\
(0.0298)\end{array}$ & $\begin{array}{l}0.0565 * * * \\
(0.0169)\end{array}$ & $\begin{array}{l}0.0447 * * * \\
(0.0181)\end{array}$ \\
\hline RWE & $\begin{array}{l}0.0152 * * \\
(0.0090)\end{array}$ & $\begin{array}{l}0.0122 * \\
(0.0085)\end{array}$ & $\begin{array}{l}0.0429 * * * \\
(0.0160)\end{array}$ & $\begin{array}{l}0.0353 * * \\
(0.0176)\end{array}$ & $\begin{array}{l}0.0102 \\
(0.0144)\end{array}$ & $\begin{array}{l}0.0272 * * \\
(0.0147)\end{array}$ \\
\hline $\mathrm{SGO}$ & $\begin{array}{c}-0.0108 \\
(0.0211)\end{array}$ & $\begin{array}{c}-0.0038 \\
(0.0212)\end{array}$ & $\begin{array}{l}0.0169 * * \\
(0.0142)\end{array}$ & $\begin{array}{l}0.0068 * \\
(0.0102)\end{array}$ & $\begin{array}{l}0.0731 * * * \\
(0.0225)\end{array}$ & $\begin{array}{l}0.0834 * * * \\
(0.0192)\end{array}$ \\
\hline SOL & $\begin{array}{l}0.0345 * * * \\
(0.0123)\end{array}$ & $\begin{array}{l}0.0135 \\
(0.0115)\end{array}$ & $\begin{array}{l}0.0598 * * * \\
(0.0234)\end{array}$ & $\begin{array}{l}0.044 * * \\
(0.0214)\end{array}$ & $\begin{array}{l}0.021 \\
(0.0201)\end{array}$ & $\begin{array}{l}0.0826 * * * \\
(0.0234)\end{array}$ \\
\hline STD & $\begin{array}{l}0.0146 \\
(0.0110)\end{array}$ & $\begin{array}{l}0.039 * * * \\
(0.0129)\end{array}$ & $\begin{array}{l}0.0276 * * \\
(0.0168)\end{array}$ & $\begin{array}{l}0.0207 * * \\
(0.0131)\end{array}$ & $\begin{array}{l}0.0234 * * \\
(0.0153)\end{array}$ & $\begin{array}{l}0.0404 * * * \\
(0.0131)\end{array}$ \\
\hline TEF & $\begin{array}{l}0.0044 \\
(0.0107)\end{array}$ & $\begin{array}{l}0.0062 \\
(0.0102)\end{array}$ & $\begin{array}{l}0.0517 * * * \\
(0.0186)\end{array}$ & $\begin{array}{l}0.0625 * * * \\
(0.0193)\end{array}$ & $\begin{array}{l}0.0449 * * * \\
(0.0191)\end{array}$ & $\begin{array}{l}0.0566 * * * \\
(0.0212)\end{array}$ \\
\hline TIT & $\begin{array}{l}0.0352 * * \\
(0.0229)\end{array}$ & $\begin{array}{l}0.0148 \\
(0.0236)\end{array}$ & $\begin{array}{l}0.0602 * * * \\
(0.0185)\end{array}$ & $\begin{array}{l}0.055 * * * \\
(0.0173)\end{array}$ & $\begin{array}{l}0.0644 * * * \\
(0.0185)\end{array}$ & $\begin{array}{l}0.056 * * * \\
(0.0177)\end{array}$ \\
\hline VAT & $\begin{array}{c}-0.0052 \\
(0.0106)\end{array}$ & $\begin{array}{l}0.0077 \\
(0.0108)\end{array}$ & $\begin{array}{l}0.073 * * * \\
(0.0217)\end{array}$ & $\begin{array}{l}0.0438 * * \\
(0.0210)\end{array}$ & $\begin{array}{l}0.0197 \\
(0.0180)\end{array}$ & $\begin{array}{l}0.0532 * * * \\
(0.0198)\end{array}$ \\
\hline VE & $\begin{array}{l}0.0139 * * \\
(0.0067)\end{array}$ & $\begin{array}{l}0.0062 \\
(0.0083)\end{array}$ & $\begin{array}{l}0.0631 * * * \\
(0.0224)\end{array}$ & $\begin{array}{l}0.0694 * * * \\
(0.0240)\end{array}$ & $\begin{array}{l}0.0234 * \\
(0.0187)\end{array}$ & $\begin{array}{l}0.0434 * * * \\
(0.0191)\end{array}$ \\
\hline VOW & $\begin{array}{l}0.0563 * * * \\
(0.0148)\end{array}$ & $\begin{array}{l}0.0558 * * * \\
(0.0139)\end{array}$ & $\begin{array}{l}0.0398 * * * \\
(0.0163)\end{array}$ & $\begin{array}{l}0.0327 * * \\
(0.0165)\end{array}$ & $\begin{array}{l}0.0556 * * * \\
(0.0168)\end{array}$ & $\begin{array}{l}0.0344 * * \\
(0.0163)\end{array}$ \\
\hline
\end{tabular}

Table 3: Effective transfer entropy estimates: pre-crisis, crisis and after crisis phase

The table shows effective transfer entropy estimates from the CDS to the bond market,

$\mathrm{ET}(\mathrm{CDS} \rightarrow \mathrm{CS})$ and from the bond to the CDS market, ET(CS $\rightarrow \mathrm{CDS})$. Standard errors derived

from the bootstrap procedure outlined in Section 3 using 1000 simulation runs are given in parentheses. $* * *, * * *$ indicate significance at the $10,5,1 \%$ significance level. 


\begin{tabular}{|c|c|c|c|c|}
\hline \multicolumn{2}{|c|}{ Quantiles } & ET $^{\text {boot }}($ iTraxx $\rightarrow$ VIX $)$ & $\mathrm{ET}^{\text {boot }}(\mathrm{VIX} \rightarrow \mathrm{i} \operatorname{Traxx})$ & DIFF \\
\hline$q_{1}$ & $q_{2}$ & 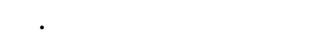 & . & \\
\hline 5 & 95 & $\begin{array}{l}0.0409 * * * \\
(0.0089)\end{array}$ & $\begin{array}{l}0.0518 * * * \\
(0.0106)\end{array}$ & -0.0109 \\
\hline 10 & 90 & $\begin{array}{l}0.0303 * \\
(0.0298)\end{array}$ & $\begin{array}{l}0.0665 * * * \\
(0.0306)\end{array}$ & -0.0362 \\
\hline 15 & 85 & $\begin{array}{c}-0.0404 \\
(0.0391)\end{array}$ & $\begin{array}{l}0.0351 \\
(0.0381)\end{array}$ & $-0.0755^{* *}$ \\
\hline 20 & 80 & $\begin{array}{l}0.0213 * * * \\
(0.0071)\end{array}$ & $\begin{array}{l}0.0303 * * * \\
(0.0083)\end{array}$ & -0.0089 \\
\hline 25 & 75 & $\begin{array}{c}-0.2968 \\
(0.0369)\end{array}$ & $\begin{array}{c}-0.2750 \\
(0.0380)\end{array}$ & -0.0218 \\
\hline
\end{tabular}

Table 4: Effective transfer entropy for VIX and iTraxx

The table shows the effective transfer entropy from VIX to iTraxx series and vice versa. All measures are calculated with the data seperated into three bins according to the quantiles in the first two columns (compare Equation (6)). The last column gives the difference between both estimates, so that negative (positive) values indicate a larger information flow from the VIX (iTraxx) to the iTraxx (VIX). Bootstrapped standard errors using 1000 simulation runs are given in parentheses. $*, * *, * * *$ denote statistical significance on the $10,5,1 \%$ level of significance.

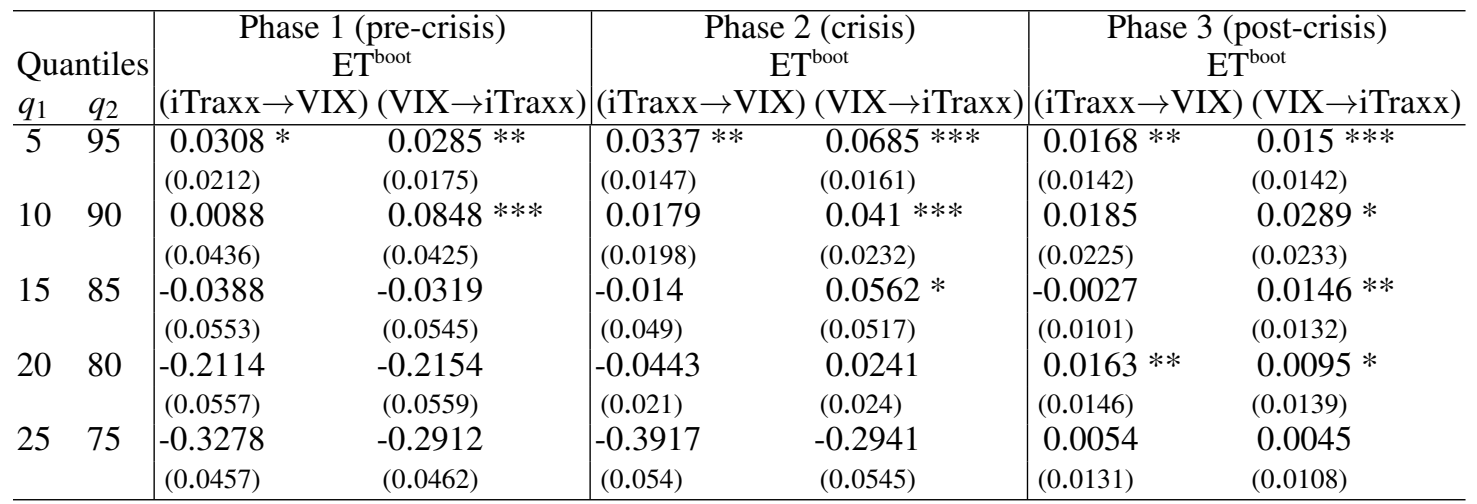

Table 5: Effective transfer entropy for VIX and iTraxx: pre-, crisis and after crisis phase

The table shows the effective transfer entropy from VIX to iTraxx series and vice versa. All measures are calculated with the data seperated into three bins according to the quantiles in the first two columns (compare Equation (6)). Bootstrapped standard errors using 1000 simulation runs are given in parentheses. $* * *, * * *$ denote statistical significance on the $10,5,1 \%$ level of significance. 


\section{SFB 649 Discussion Paper Series 2012}

For a complete list of Discussion Papers published by the SFB 649, please visit http://sfb649.wiwi.hu-berlin.de.

001 "HMM in dynamic HAC models" by Wolfgang Karl Härdle, Ostap Okhrin and Weining Wang, January 2012.

002 "Dynamic Activity Analysis Model Based Win-Win Development Forecasting Under the Environmental Regulation in China" by Shiyi Chen and Wolfgang Karl Härdle, January 2012.

003 "A Donsker Theorem for Lévy Measures" by Richard Nickl and Markus Reiß, January 2012.

004 "Computational Statistics (Journal)" by Wolfgang Karl Härdle, Yuichi Mori and Jürgen Symanzik, January 2012.

005 "Implementing quotas in university admissions: An experimental analysis" by Sebastian Braun, Nadja Dwenger, Dorothea Kübler and Alexander Westkamp, January 2012.

006 "Quantile Regression in Risk Calibration" by Shih-Kang Chao, Wolfgang Karl Härdle and Weining Wang, January 2012.

007 "Total Work and Gender: Facts and Possible Explanations" by Michael Burda, Daniel S. Hamermesh and Philippe Weil, February 2012.

008 "Does Basel II Pillar 3 Risk Exposure Data help to Identify Risky Banks?" by Ralf Sabiwalsky, February 2012.

009 "Comparability Effects of Mandatory IFRS Adoption" by Stefano Cascino and Joachim Gassen, February 2012.

010 "Fair Value Reclassifications of Financial Assets during the Financial Crisis" by Jannis Bischof, Ulf Brüggemann and Holger Daske, February 2012.

011 "Intended and unintended consequences of mandatory IFRS adoption: A review of extant evidence and suggestions for future research" by Ulf Brüggemann, Jörg-Markus Hitz and Thorsten Sellhorn, February 2012.

012 "Confidence sets in nonparametric calibration of exponential Lévy models" by Jakob Söhl, February 2012.

013 "The Polarization of Employment in German Local Labor Markets" by Charlotte Senftleben and Hanna Wielandt, February 2012.

014 "On the Dark Side of the Market: Identifying and Analyzing Hidden Order Placements" by Nikolaus Hautsch and Ruihong Huang, February 2012.

015 "Existence and Uniqueness of Perturbation Solutions to DSGE Models" by Hong Lan and Alexander Meyer-Gohde, February 2012.

016 "Nonparametric adaptive estimation of linear functionals for low frequency observed Lévy processes" by Johanna Kappus, February 2012.

017 "Option calibration of exponential Lévy models: Implementation and empirical results" by Jakob Söhl und Mathias Trabs, February 2012.

018 "Managerial Overconfidence and Corporate Risk Management" by Tim R. Adam, Chitru S. Fernando and Evgenia Golubeva, February 2012.

019 "Why Do Firms Engage in Selective Hedging?" by Tim R. Adam, Chitru S. Fernando and Jesus M. Salas, February 2012.

020 "A Slab in the Face: Building Quality and Neighborhood Effects" by Rainer Schulz and Martin Wersing, February 2012.

021 "A Strategy Perspective on the Performance Relevance of the CFO" by Andreas Venus and Andreas Engelen, February 2012.

022 "Assessing the Anchoring of Inflation Expectations" by Till Strohsal and Lars Winkelmann, February 2012.

\section{SFB 649, Spandauer Straße 1, D-10178 Berlin http://sfb649.wiwi.hu-berlin.de}

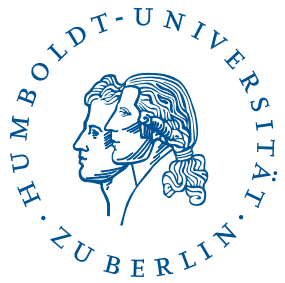




\section{SFB 649 Discussion Paper Series 2012}

For a complete list of Discussion Papers published by the SFB 649, please visit http://sfb649.wiwi.hu-berlin.de.

023 "Hidden Liquidity: Determinants and Impact" by Gökhan Cebiroglu and Ulrich Horst, March 2012.

024 "Bye Bye, G.I. - The Impact of the U.S. Military Drawdown on Local German Labor Markets" by Jan Peter aus dem Moore and Alexandra Spitz-Oener, March 2012.

025 "Is socially responsible investing just screening? Evidence from mutual funds" by Markus Hirschberger, Ralph E. Steuer, Sebastian Utz and Maximilian Wimmer, March 2012.

026 "Explaining regional unemployment differences in Germany: a spatial panel data analysis" by Franziska Lottmann, March 2012.

027 "Forecast based Pricing of Weather Derivatives" by Wolfgang Karl Härdle, Brenda López-Cabrera and Matthias Ritter, March 2012.

028 "Does umbrella branding really work? Investigating cross-category brand loyalty" by Nadja Silberhorn and Lutz Hildebrandt, April 2012.

029 "Statistical Modelling of Temperature Risk" by Zografia Anastasiadou, and Brenda López-Cabrera, April 2012.

030 "Support Vector Machines with Evolutionary Feature Selection for Default Prediction" by Wolfgang Karl Härdle, Dedy Dwi Prastyo and Christian Hafner, April 2012.

031 "Local Adaptive Multiplicative Error Models for High-Frequency Forecasts" by Wolfgang Karl Härdle, Nikolaus Hautsch and Andrija Mihoci, April 2012.

032 "Copula Dynamics in CDOs." by Barbara Choroś-Tomczyk, Wolfgang Karl Härdle and Ludger Overbeck, May 2012.

033 "Simultaneous Statistical Inference in Dynamic Factor Models" by Thorsten Dickhaus, May 2012.

034 "Realized Copula" by Matthias R. Fengler and Ostap Okhrin, Mai 2012.

035 "Correlated Trades and Herd Behavior in the Stock Market" by Simon Jurkatis, Stephanie Kremer and Dieter Nautz, May 2012

036 "Hierarchical Archimedean Copulae: The HAC Package" by Ostap Okhrin and Alexander Ristig, May 2012.

037 "Do Japanese Stock Prices Reflect Macro Fundamentals?" by Wenjuan Chen and Anton Velinov, May 2012.

038 "The Aging Investor: Insights from Neuroeconomics" by Peter N. C. Mohr and Hauke R. Heekeren, May 2012.

039 "Volatility of price indices for heterogeneous goods" by Fabian Y.R.P. Bocart and Christian M. Hafner, May 2012.

040 "Location, location, location: Extracting location value from house prices" by Jens Kolbe, Rainer Schulz, Martin Wersing and Axel Werwatz, May 2012.

041 "Multiple point hypothesis test problems and effective numbers of tests" by Thorsten Dickhaus and Jens Stange, June 2012

042 "Generated Covariates in Nonparametric Estimation: A Short Review." by Enno Mammen, Christoph Rothe, and Melanie Schienle, June 2012.

043 "The Signal of Volatility" by Till Strohsal and Enzo Weber, June 2012.

044 "Copula-Based Dynamic Conditional Correlation Multiplicative Error Processes" by Taras Bodnar and Nikolaus Hautsch, July 2012

\section{SFB 649, Spandauer Straße 1, D-10178 Berlin http://sfb649.wiwi.hu-berlin.de}




\section{SFB 649 Discussion Paper Series 2012}

For a complete list of Discussion Papers published by the SFB 649, please visit http://sfb649.wiwi.hu-berlin.de.

045 "Additive Models: Extensions and Related Models." by Enno Mammen, Byeong U. Park and Melanie Schienle, July 2012.

046 "A uniform central limit theorem and efficiency for deconvolution estimators" by Jakob Söhl and Mathias Trabs, July 2012

047 "Nonparametric Kernel Density Estimation Near the Boundary" by Peter Malec and Melanie Schienle, August 2012

048 "Yield Curve Modeling and Forecasting using Semiparametric Factor Dynamics" by Wolfgang Karl Härdle and Piotr Majer, August 2012

049 "Simultaneous test procedures in terms of $p$-value copulae" by Thorsten Dickhaus and Jakob Gierl, August 2012

050 "Do Natural Resource Sectors Rely Less on External Finance than Manufacturing Sectors? " by Christian Hattendorff, August 2012

051 "Using transfer entropy to measure information flows between financial markets" by Thomas Dimpfl and Franziska J. Peter, August 2012 